\title{
Effects of hospital generic drug substitution on diabetes therapy
}

\author{
This article was published in the following Dove Press journal: \\ Patient Preference and Adherence \\ 29 January 2014 \\ Number of times this article has been viewed
}

\author{
Hui-Yin Chen' \\ Hui-Ru Chang ${ }^{2}$ \\ Hui-Chu Lang ${ }^{3}$ \\ 'Department of Auditing, Mackay \\ Memorial Hospital, Taipei, Taiwan; \\ ${ }^{2}$ Department of Social Insurance, \\ Ministry of Health and Welfare, Taipei, \\ Taiwan; ${ }^{3}$ nstitute of Hospital and \\ Health Care Administration, National \\ Yang-Ming University, Taipei, Taiwan
}

Objectives: To evaluate the effects on physicians' prescribing behavior and on the therapeutic outcome of non-insulin-dependent diabetes patients of substituting different generic brands of metformin.

Methods: We adopt a retrospective cohort study involving 280 type- 2 diabetes patients who regularly used the outpatient services of one medical center and who had changed metformin brands five times between 2003 and 2008. The aim was to examine the effects of switching brands. The generalized estimating equation was used to determine whether drug brand switching affected patient glycated hemoglobin $\mathrm{A}_{1 \mathrm{c}}\left(\mathrm{HbA}_{\mathrm{lc}}\right)$ levels, their prescribed daily dose, or their adherence to medication with metformin.

Results: $\mathrm{HbA}_{1 \mathrm{c}}$ levels increased from 7.91 to 8.34 throughout the study period, although it was found that brand switching did not adversely affect $\mathrm{HbA}_{1 \mathrm{c}}$ levels after controlling for patient characteristics and the time course of the study. Furthermore, the prescribed daily dose of metformin was stable throughout the study period, and was approximately 0.8 of the defined daily dose. Finally, although adherence was significantly higher with the original metformin than with the four generic brands, patients still maintained high levels of adherence of $>0.8$.

Conclusion: Although switching between different brands of metformin slightly affected the prescribing behavior of the physicians, there was no unfavorable effect on patient $\mathrm{HbA}_{\mathrm{lc}}$ levels. Thus, the policy of substituting between different generic brands of metformin is a good costeffective approach that does not adversely affect the quality of diabetes patient care.

Keywords: metformin, generic substitution, glycemic control, prescribing behavior, adherence

\section{Introduction}

In Taiwan, pharmaceutical expenditure regularly accounts for around $25 \%$ of total health spending each year. ${ }^{1}$ The rapid growth of pharmaceutical expenditure has put pressure on both payers and providers and created a need to implement cost-effective approaches that are able to limit this type of expenditure. One common and efficient method of controlling the cost of pharmaceuticals is the use of generic substitution. Liu et $\mathrm{al}^{2}$ indicated that the financial incentive offered by drug price deviation is the major driving force when physicians switch from a branded drug to its generic version. However, previous studies have not investigated the potential effects of switching between a branded drug and a generic drug after price adjustments. In addition, most previous studies have been concerned with reducing costs; thus, in the present study, we have focused on a practice outcome, namely the level of glycated hemoglobin $\left(\mathrm{HbA}_{1 \mathrm{c}}\right)$, and on physician behavior, including the prescribed daily dose (PDD) of metformin and
Correspondence: Hui-Chu Lang Institute of Hospital and Health Care Administration, National Yang-Ming University, No 155 Sec 2 Li-Nong Street, Taipei I 12, Taiwan

Tel +8862282670I5

Email hclang@ym.edu.tw 
all other classes of oral anti-diabetes drugs. In addition, we have explored patient adherence before and after substitution. All studies were carried out at the same hospital.

In the last two decades, there has been an increase in research into generic substitution. Some studies have found that generic substitution is cost effective; ${ }^{3,4}$ while several others have suggested that generic substitution results in a higher level of health care utilization for certain diseases. ${ }^{5,6}$ Despite the fact that generic drugs have to be bioequivalent to the brand-name drug, there are some doubts, and it has been suggested that over-prescription of generic drugs occurs. The major concerns in this area are that the rate and extent of absorption might differ between the generic and the brandname drug and that this may in turn affect the therapeutic efficacy. ${ }^{7}$ Furthermore, the patient perspective of generic drugs may also have an influence on drug adherence to the therapy, and this might result in the doubling of doses, poor compliance, or a cessation of therapy. ${ }^{8,9}$ In addition, physicians might feel that a generic drug is not of as high a quality and not as effective as the branded equivalent drug, and this may be a barrier affecting the use of generic substitutes. ${ }^{10}$

Recently, strict certification of generic drugs, as well as price competition policies, have been implemented in European countries, and this had led to a more positive attitude toward the use of generic drugs. ${ }^{11,12}$ In Taiwan, pharmacists dispense medication strictly according to the doctor's prescription, and they are unable to replace the prescribed drug with its equivalent or with a generic substitute without permission. Thus, doctors control the brand of the medication that the patient receives. As a result, most research on generic substitution has focused on the attitude of physicians, patients, and pharmacists, as well as on examining the bioequivalence of generic drugs. Additionally, the clinical outcomes when generic drug substitution occurs have been widely investigated, and a growing body of research has shed some light on the efficacy of generic drugs. ${ }^{13}$ However, doubt remains as to whether the bioequivalence of generic drugs is identical to the therapeutic equivalence. Only a few studies have focused on the therapeutic effectiveness of generic drugs from different manufacturers. ${ }^{14}$

Globally, it is estimated that the number of people with diabetes will increase from 25 million in 2000 to 366 million in 2030; ${ }^{15}$ such an increase will impose a heavy economic burden on health care systems. Due to the high cost associated with anti-diabetes medications, there is a need to examine generic substitution. Among the different classes of anti-diabetes drugs, metformin has been rapidly adopted due to its designation as a first-line therapy, and it became the leading class of prescribed anti-diabetic drug in 2004. ${ }^{16}$ Therefore, the present study focuses on the influence of generic substitution with respect to metformin, the most widely used oral anti-diabetes drug used on diabetes patients. In this study, we examine the effects of substituting metformin produced by different manufacturers on the prescribing behavior of physicians and examine the therapeutic effectiveness of the different forms of metformin, both at a single medical center. Specifically, the present study used longitudinal follow-up data to examine the influence of brand switching on both the prescribing behavior of the physicians and on the treatment outcome with respect to the diabetes patients.

\section{Methods}

This study is a retrospective longitudinal study that was conducted at a single medical center in Taiwan. This particular medical center had changed metformin brands five times between July 2003 and July 2008. Initially, the branded drug Glucophage ${ }^{\circledR}$ (Merck Sante SAS, Lyon Cedex, France) was prescribed. This was then followed by four generic brands of metformin from four different manufacturers. The period of prescription of each brand of metformin was as follows: prescription of the branded drug I ended on July 12, 2004; generic drug II was prescribed from July 13, 2004 to November 2, 2005; generic drug III was prescribed from November 3, 2005 to August 11, 2006; generic drug II was prescribed from August 12, 2006 to August 15, 2007; and generic drug IV was prescribed from August 16, 2007 to August 8, 2008. Therefore, we divided the study period into five stages based on the brand-switching periods. We then identified type-2 diabetes patients who regularly used the outpatient services of the hospital and had continuously taken metformin throughout the study period; these patients were our initial study group. Of the patients identified, 280 individuals fitted the selection criteria and formed the study cohort. We then retrospectively analyzed the prescribing behavior of the physicians and the patients' treatment outcomes for each of the generic metformin drugs as well as for Glucophage ${ }^{\circledR}$. Metformin was selected as the main study drug for observing the effect of brand switching because of the large study population available. In addition, to evaluate any changes in the prescribing behavior of the physicians, we also analyzed the use of all other oral anti-diabetes drugs listed by the hospital pharmacy, including acarbose, glimepiride, glibenclamid, gliclazide, repaglinide, nateglinide, rosiglitazone, and pioglitazone. This study proposal was 
approved by the hospital institutional review board before it was conducted.

To evaluate any changes in the patients' treatment outcomes for each metformin brand, we collected the patients' $\mathrm{HbA}_{1 \mathrm{c}}$ concentrations from their medical records between July 2003 and July 2008. The $\mathrm{HbA}_{1 \mathrm{c}}$ test is a reliable method of monitoring diabetes control, and the American Diabetes Association recommends a target level of $<7.0 \%$ for nonpregnant adults. ${ }^{17}$ Therefore, the outcome measurement we used for evaluating whether or not drug brand switching affected glycemic control was $\mathrm{HbA}_{1 \mathrm{c}}$ concentration. If the $\mathrm{HbA}_{1 \mathrm{c}}$ levels were significantly higher among patients that were prescribed the generic brand than among those that were prescribed Glucophage ${ }^{\circledR}$, then this could imply that the generic drugs did not have the same therapeutic effect as the brandname drug.

The generic drugs from the different manufacturers were bioequivalent to the original drug and, in theory, should be clinically equivalent. Therefore, we hypothesized that physicians ought not to change the dosage of a generic drug when switching between suppliers. Prescription data were collected to evaluate the prescribing behavior of the physicians throughout the five periods of brand switching. The PDD, or the average daily amount of a drug prescribed by a physician, was calculated for every patient, as these adequately reflected patient drug exposure. Furthermore, the PDD of each oral anti-diabetes drug was expressed as the defined daily dose (DDD), according to the Anatomical Therapeutic Chemical Classification/Defined Daily Doses (ATC/DDD) system. ${ }^{18}$ The use of DDD is a convenient approach when comparing the dosage of different drug classes. If either the physician or the patient has doubts regarding the equivalence of a generic drug, then the drug adherence might be affected. ${ }^{19}$ Therefore, in addition to the PDD, drug adherence was also measured to evaluate any effect the prescribing behavior of the physician might have. We used the medication possession ratio as an index of adherence; this was calculated for each brand by dividing the number of drug days supplied by the number of days. ${ }^{20}$

In addition we collected the demographic characteristics of the patients at baseline, including age, sex, and disease severity. Age was grouped into four categories, as $<50$, $50-59,60-69$, and $\geq 70$ years of age. The Deyo-Charlson comorbidity index (CCI) was calculated for each patient using the baseline discharge claims data. This index is a summary weighted score based on the presence or absence of 17 medical conditions and can be used to quantify a patient's comorbidities. $^{21}$
Since the data collected were longitudinal, ordinary least squares regression may have led to incorrect regression coefficients if we ignored the dependence of the data. In addition, the $\mathrm{HbA}_{1 \mathrm{c}}$ testing frequency for each patient was different and occurred more frequently when a patient's condition was more unstable. Therefore, the generalized estimating equation (GEE) was applied to allow differentiation of the cohort effects of the multiple measures. This approach provides consistent parameter estimates for the fixed effects. Using the GEE models, we determined whether brand switching affected the patients' $\mathrm{HbA}_{1 \mathrm{c}}$ levels, PDD, and adherence after adjusting for age, sex, and CCI. Due to the fact that $\mathrm{HbA}_{1 \mathrm{c}}$ levels are known to increase with age, ${ }^{22}$ and given that the frequency of $\mathrm{HbA}_{1 \mathrm{c}}$ measurements did vary and were not the same across all patients, a time variable was incorporated into the GEE model. Specifically, the time variable was the number of days from the beginning of the study period to a given $\mathrm{HbA}_{1 \mathrm{c}}$ test date. SAS (SAS Institute Inc, Cary, NC, USA) software, version 9.1, was used for all statistical analyses. All $P$-values were calculated for two-tailed tests, with a statistical significant difference being defined as $P \leq 0.05$.

\section{Results}

Baseline patient characteristics, $\mathrm{HbA}_{1 \mathrm{c}}$ levels, PDD, and adherence to metformin stratified by the different periods of brand switching are summarized in Table 1. Of the 280 participants, $57 \%$ were female and $43 \%$ were male, and their mean age was 59.6 years. Half of the patients had a CCI of 1 , while $40 \%$ had a CCI of 2 , and $9 \%$ had a CCI of 3 or more. During the follow-up period, $\mathrm{HbA}_{1 \mathrm{c}}$ levels gradually increased, especially among the males and low-severity subjects. The PDD for metformin across the patients was stable throughout the study period and was approximately 0.8 DDDs. Conversely, the adherence to metformin gradually decreased in the various subgroups that had different characteristics. The adherence for females decreased from 0.96 to 0.83 , and the adherence for males decreased from 0.94 to 0.82 . Overall, the adherence decrease was from 0.95 to 0.83 throughout the study period.

The correlations between the different brand periods and $\mathrm{HbA}_{1 \mathrm{c}}$ levels, $\mathrm{PDD}$, and adherence to metformin, after controlling for patient characteristics, are shown in Table 2. The significant predicators of $\mathrm{HbA}_{1 \mathrm{c}}$ levels were brand stage and CCI. $\mathrm{HbA}_{1 \mathrm{c}}$ levels were found to be significantly lower when the generic drug during stage II was used compared with the use of the branded drug $(\beta=-0.16, P=0.033)$. During other periods, there were no significant differences 


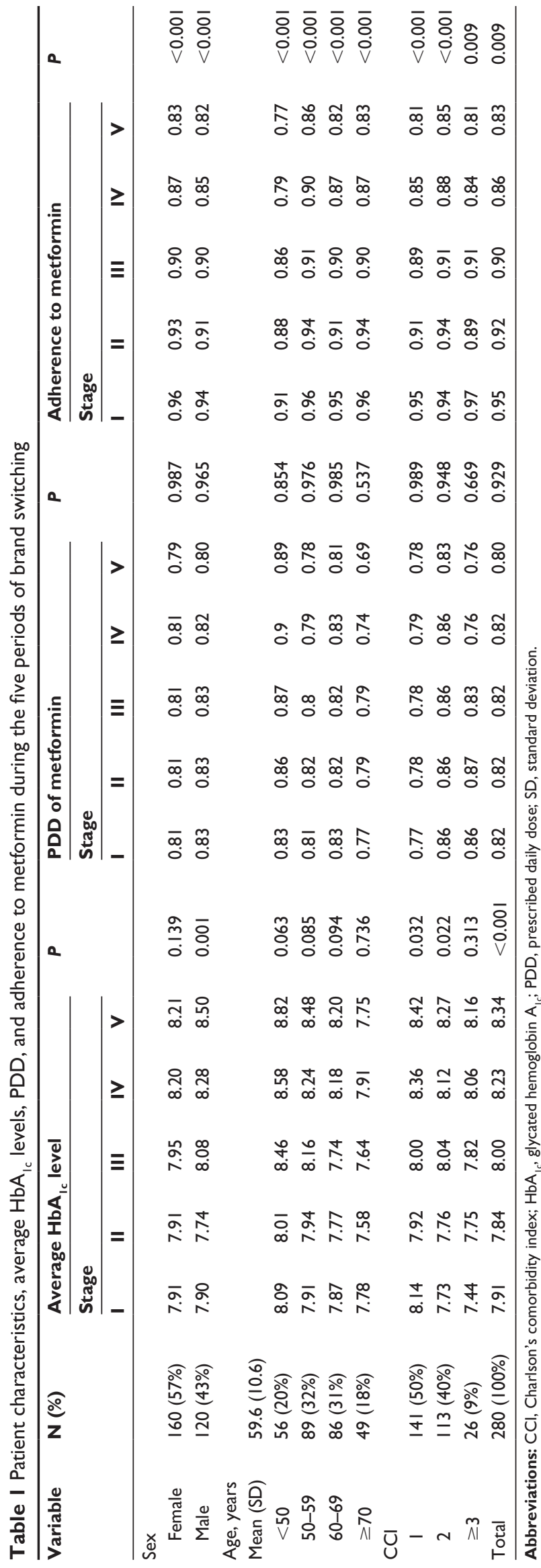

in $\mathrm{HbA}_{1 \mathrm{c}}$ levels when the branded drug was used in relation to the generic substitutes used later. In addition, $\mathrm{HbA}_{1 \mathrm{c}}$ levels among the oldest group of subjects were statistically lower than those among the youngest group $(\beta=-0.56, P=0.013)$. When the PDD of metformin was examined, the significant predictors were age and CCI. Patients with an age of $\geq 70$ years had a lower PDD than those with an age of $<50$ years ( $\beta=-0.13, P=0.023)$. Furthermore, patients with a CCI of 2 had a higher PDD than those with a CCI of $1(\beta=0.07$, $P=0.046$ ). After controlling for sex, age, and CCI, brand switching did not significantly predict PDD. The significant predictors of adherence were stage and age. Overall, adherence was significantly higher with the branded drug than with the other four generic substitutes $(P<0.001)$. Furthermore, patients aged $<50$ years had a lower adherence compared with those aged $\geq 50$ years.

The PDDs of the other classes of oral anti-diabetes drugs over the five different periods of brand switching are summarized in Table 3. The number of patients prescribed acarbose, glimepiride, or pioglitazone increased throughout the study period. Among these drugs, glimepiride was the most frequently used, and its PDD increased significantly from 2.19 to $2.60 \mathrm{DDDs}(P=0.026)$. However, there were no statistically significant changes in the PDD of the other anti-diabetes drugs over the time period of this study. The magnitudes of change in the PDDs of these drugs were quite small.

\section{Discussion}

In the present study, despite the fact that there was a trend of increasing $\mathrm{HbA}_{1 \mathrm{c}}$ levels throughout the study period, there was no significant deterioration in $\mathrm{HbA}_{1 \mathrm{c}}$ levels following brand switching, based on the GEE model. After controlling for the independent variables, namely sex, age, disease severity, and the time course from baseline to $\mathrm{HbA}_{1 \mathrm{c}}$ measurement, there was a significant improvement in the $\mathrm{HbA}_{1 \mathrm{c}}$ values compared with the original branded drug, but there were no significant differences in $\mathrm{HbA}_{1 \mathrm{c}}$ levels for the remaining three stages of the generic substitutions.

In the 1990 s, there was uncertainty regarding the quality of generic drugs as a result of the implementation of policies that simplified approval requirements to increase generic competition. In addition, scandals involving bribery of quality control-approving authorities in the US and Europe complicated matters even further, ${ }^{23}$ not to mention the fact that there were major concerns regarding poor drug compliance and drug discontinuation with respect to generic substitutions; all this was believed to result in poorer treatment outcomes. 
Table 2 Regression coefficients obtained using the generalized estimating equations for variables predicting $\mathrm{HbA}_{\mathrm{Ic}}$ levels, PDD, and adherence

\begin{tabular}{|c|c|c|c|c|c|c|c|c|c|}
\hline \multirow[t]{2}{*}{ Variable } & \multicolumn{3}{|c|}{ HbA $_{\mathrm{lc}}$ level } & \multicolumn{3}{|c|}{ PDD of metformin } & \multicolumn{3}{|c|}{ Adherence to metformin } \\
\hline & $\beta$ & $95 \% \mathrm{Cl}$ & $P$ & $\beta$ & $95 \% \mathrm{Cl}$ & $P$ & $\beta$ & $95 \% \mathrm{Cl}$ & $P$ \\
\hline \multicolumn{10}{|l|}{ Stage } \\
\hline \multicolumn{10}{|c|}{ I (reference) } \\
\hline II & -0.16 & $(-0.3 \mathrm{I},-0.0 \mathrm{I})$ & 0.033 & 0.00 & $(-0.01,0.02)$ & 0.602 & -0.03 & $(-0.04,-0.01)$ & $<0.001$ \\
\hline III & -0.04 & $(-0.28,0.19)$ & 0.725 & 0.00 & $(-0.02,0.03)$ & 0.780 & -0.05 & $(-0.07,-0.03)$ & $<0.001$ \\
\hline IV & 0.12 & $(-0.19,0.42)$ & 0.459 & 0.00 & $(-0.03,0.03)$ & 1.000 & -0.08 & $(-0.11,-0.06)$ & $<0.001$ \\
\hline $\mathrm{V}$ & 0.09 & $(-0.31,0.48)$ & 0.672 & -0.02 & $(-0.06,0.02)$ & 0.332 & -0.12 & $(-0.15,-0.10)$ & $<0.001$ \\
\hline \multicolumn{10}{|l|}{ Sex } \\
\hline \multicolumn{10}{|c|}{ Female (reference) } \\
\hline Male & 0.05 & $(-0.24,0.34)$ & 0.719 & 0.00 & $(-0.08,0.07)$ & 0.900 & -0.01 & $(-0.03,0.02)$ & 0.614 \\
\hline \multicolumn{10}{|c|}{ Age (years) } \\
\hline \multicolumn{10}{|c|}{$<50$ (reference) } \\
\hline $50-59$ & -0.18 & $(-0.61,0.25)$ & 0.412 & -0.07 & $(-0.17,0.04)$ & 0.198 & 0.07 & $(0.03,0.11)$ & 0.001 \\
\hline $60-69$ & -0.36 & $(-0.78,0.06)$ & 0.092 & -0.05 & $(-0.15,0.05)$ & 0.362 & 0.04 & $(0.00,0.09)$ & 0.036 \\
\hline$\geq 70$ & -0.56 & $(-1.00,-0.12)$ & 0.013 & -0.13 & $(-0.24,-0.02)$ & 0.023 & 0.05 & $(0.01,0.10)$ & 0.015 \\
\hline \multicolumn{10}{|l|}{$\mathrm{CCl}$} \\
\hline \multicolumn{10}{|c|}{ I (reference) } \\
\hline 2 & -0.23 & $(-0.53,0.07)$ & 0.139 & 0.07 & $(0.00,0.15)$ & 0.046 & 0.02 & $(0.00,0.05)$ & 0.062 \\
\hline$\geq 3$ & -0.30 & $(-0.73,0.12)$ & 0.164 & 0.05 & $(-0.08,0.18)$ & 0.472 & 0.01 & $(-0.04,0.06)$ & 0.643 \\
\hline Time $^{\mathrm{a}}$ & 0.00 & $(0.00,-0.00)$ & 0.171 & & & & & & \\
\hline
\end{tabular}

Note: ${ }^{\text {TT }}$ The number of days from the beginning of the study period to the given $\mathrm{HbA}_{\mathrm{Ic}}$ test date.

Abbreviations: $\mathrm{CCl}$, Charlson's comorbidity index; $\mathrm{Cl}$, confidence interval; $\mathrm{HbA}_{1 \mathrm{c}}$, glycated hemoglobin $\mathrm{A}_{1 \mathrm{c}}$; PDD, prescribed daily dose.

More recently, however, studies have shown that uncertainty among physicians regarding the quality of generics has declined, and acceptance regarding prescription of generic drugs has increased.

In the case of metformin, studies have shown the bioequivalence of generic substitutes and, furthermore, it has also been shown that generic drugs demonstrate similar therapeutic effects compared with the brand-name medication. ${ }^{24-26}$ This observation was confirmed in the present study, indicating that the study hospital was able to successfully ensure drug quality when they adopted the use of generic drugs. The drug-purchasing committee of the study hospital needs to be certain that the completed bioequivalence tests are robust enough to support the procurement process, and in addition, they must continuously monitor newly adopted generic substitute drugs, even if those drugs have been listed on the National Health Insurance reimbursement list. Thus, it is suggested that strict certification of generic drugs is necessary to ensure drug quality; the establishment of such strict regulations will boost the confidence of both physicians prescribing the generic drugs and patients using the generic drugs. ${ }^{27}$

Table 3 The prescribed daily dose of the other classes of oral anti-diabetes drugs over the different periods of brand switching

\begin{tabular}{|c|c|c|c|c|c|c|c|c|c|c|c|c|c|c|c|c|}
\hline \multirow[t]{2}{*}{ Stage } & \multicolumn{4}{|c|}{ Acarbose } & \multicolumn{4}{|c|}{ Glimepiride } & \multicolumn{4}{|c|}{ Glibenclamide } & \multicolumn{4}{|c|}{ Gliclazide } \\
\hline & $\mathbf{N}$ & Mean & SD & $P$ & $\mathbf{N}$ & Mean & SD & $P$ & $\mathbf{N}$ & Mean & SD & $P$ & $\mathbf{N}$ & Mean & SD & $P$ \\
\hline I & 37 & 0.56 & 0.20 & 0.129 & 109 & 2.19 & $\mathrm{I} .08$ & 0.026 & 71 & 1.35 & 0.59 & 0.966 & - & - & - & 0.949 \\
\hline II & 54 & 0.47 & 0.17 & & 118 & 2.35 & 1.12 & & 74 & 1.40 & 0.55 & & 83 & 1.22 & 0.54 & \\
\hline III & 60 & 0.49 & 0.18 & & 125 & 2.50 & 1.23 & & 66 & 1.38 & 0.54 & & 75 & 1.20 & 0.51 & \\
\hline IV & 67 & 0.48 & 0.15 & & 134 & 2.60 & 1.20 & & 58 & 1.39 & 0.53 & & 76 & 1.21 & 0.53 & \\
\hline \multirow[t]{3}{*}{ V } & 76 & 0.49 & 0.16 & & 135 & 2.60 & 1.17 & & 46 & 1.33 & 0.55 & & 81 & 1.25 & 0.52 & \\
\hline & \multicolumn{4}{|c|}{ Repaglinide } & \multicolumn{4}{|c|}{ Nateglinide } & \multicolumn{4}{|c|}{ Rosiglitazone } & \multicolumn{4}{|c|}{ Pioglitazone } \\
\hline & $\mathbf{N}$ & Mean & SD & $P$ & $\mathbf{N}$ & Mean & SD & $P$ & $\mathbf{N}$ & Mean & SD & $P$ & $\mathbf{N}$ & Mean & SD & $P$ \\
\hline I & 30 & 1.14 & 0.48 & 0.099 & - & - & - & 0.617 & 85 & 0.90 & 0.32 & 0.454 & 21 & 1.00 & 0.00 & 0.912 \\
\hline II & 31 & 1.35 & 0.42 & & 3 & 0.85 & 0.17 & & 83 & 0.87 & 0.31 & & 34 & 0.94 & 0.18 & \\
\hline III & 24 & 1.29 & 0.42 & & 7 & 0.88 & 0.16 & & 81 & 0.85 & 0.32 & & 38 & 0.94 & 0.25 & \\
\hline IV & 17 & 1.44 & 0.40 & & 4 & 0.92 & 0.17 & & 85 & 0.85 & 0.32 & & 48 & 0.93 & 0.33 & \\
\hline V & 13 & 1.46 & 0.45 & & 5 & 0.77 & 0.22 & & 61 & 0.81 & 0.29 & & 59 & 0.96 & 0.35 & \\
\hline
\end{tabular}

Abbreviation: SD, standard deviation. 
The present study used retrospective data to examine the prescribing behavior of physicians. It was found that the PDD for metformin was similar throughout the study period. However, contrary to previous studies, which found an increase in adherence as a result of substituting generic drugs, our study demonstrated a decrease in adherence after switching to generic drugs. In Taiwan, pharmacists dispense medications according to doctors' prescriptions, and they are not allowed to replace a prescribed drug with its equivalent or generic substitute. Thus, doctors control the brand of the medication a patient receives. Consequently, the financial incentives associated with value-based insurance plans, which attempt to reduce out-of-pocket costs and improve adherence to generic drugs, do not apply in Taiwan. Thus, other factors must be found that affect a physician's prescribing behavior. Metformin is the preferred first-line treatment for type-2 diabetes mellitus, as it lowers blood glucose concentrations without causing overt hypoglycemia like other oral anti-diabetes drugs. ${ }^{28}$ In the present study, although adherence to metformin was found to slightly decrease, the PDD of metformin was stable, and there was still high adherence $(>80 \%)$ to metformin throughout the study period. This suggests that physicians are confident when prescribing generic drugs. One potential reason for the decreasing trend in relation to adherence may be in part due to the use of new anti-diabetes drugs such as sulfonylureas and thiazolidinedione derivatives. During the present study, there was an increase in the number of patients using glimepiride, an oral anti-diabetes drug that has proved to be both effective and well tolerated. ${ }^{29,30}$ Furthermore, throughout the development and progression of diabetes, physicians might prescribe pioglitazone to reduce risk of cardiovascular disease.

Blood glucose levels are known to change with age. For example, $\mathrm{HbA}_{1 \mathrm{c}}$ levels have been shown to increase with age in most patients. ${ }^{31}$ However, in the present study, it was found that patients under 50 years of age had poorer glycemic control, a higher PDD, and a lower adherence compared with those $\geq 70$ years of age. Many studies have been equivocal with respect to the relationship between age and glycemic control in diabetes patients, ${ }^{32}$ and in fact, a number of studies have demonstrated poorer glycemic control among younger patients. El-Kebbi et $\mathrm{al}^{33}$ found that young patients who were hyperglycemic at an early age are at greater risk for end-organ damage. In addition, some studies have suggested that older patients might be more compliant when taking their medication, and consequently have better glycemic control. ${ }^{34,35}$ Therefore, in the present study, the lower PDD among older patients may in part be due to better glycemic control.
There are some limitations that affect the present study and need to be mentioned. First, the development and progression of diabetes and its associated comorbidities were not controlled for throughout the study period. As a result, this might have had an effect on the glycemic control of the patients and the prescribing pattern of the physicians. In addition, the drug prescription data were based only on the claim data from the study hospital, and as a result, may not include prescriptions obtained from alternative sources; this might result in an underestimation of adherence. However, given that most study subjects visited their doctor regularly at the study hospital, and seemed to be very loyal to the study hospital, this factor is likely to affect only a very small proportion of patients. Since metformin is not an expensive drug, the results of this study may not apply to more expensive drugs where cost might be a factor. In this study, we included only 280 patients who continued to take metformin throughout the study period and excluded patients who did not continue to take metformin; this might have resulted in an overestimation of adherence.

The findings of the present study demonstrate that switching between different manufacturers of metformin had only a slight effect on the prescribing behavior of the physicians. However, brand switching did not have any effect on patient $\mathrm{HbA}_{1 \mathrm{c}}$ levels. Any changes in the prescribing behavior of the physician might be due to the introduction of newer anti-diabetes drugs or to uncertainty regarding the therapeutic efficacy of the generic substitute. Thus, studies exploring the factors affecting prescribing behavior of physicians following brand switching are warranted. Furthermore, although adherence to generic metformin decreased slightly following brand switching, the PDD remained stable, and adherence remained above $80 \%$, which is still considered to be high. Thus, although the substitution of generic drugs did affect the prescribing behavior of physicians, there was no evidence to suggest that brand switching worsened glycemic control. Based on these findings, a policy of introducing metformin generic substitution appears both to be cost effective and to have no effect on the quality of care at the study hospital.

\section{Disclosure}

The authors report no conflicts of interest in this work.

\section{References}

1. Bureau of National Health Insurance (BNHI), Taiwan [http://www.nhi. gov.tw/english/index.aspx]. Accessed April 2, 2013.

2. Liu YM, Yang YH, Hsieh CR. Regulation and competition in the Taiwanese pharmaceutical market under national health insurance. $J$ Health Econ. 2012;31:471-483. 
3. Haas JS, Phillips KA, Gerstenberger EP, Seger AC. Potential savings from substituting generic drugs for brand-name drugs: Medical Expenditure Panel Survey, 1997-2000. Ann Intern Med. 2005;142:891-897.

4. Holmes CB, Coggin W, Jamieson D, et al. Use of generic antiretroviral agents and cost savings in PEPFRA treatment programs. JAMA. 2010;304:313-120.

5. Helmers SL, Paradis PE, Manjunath R, et al. Economic burden associated with the use of generic antiepileptic drugs in the United States. Epilepsy Behav. 2010;18:437-444.

6. Johnston A, Asmar R, Dahlöf B, et al. Generic and therapeutic substitution: a viewpoint on achieving best practice in Europe. Br J Clin Pharmacol. 2011;72(5):727-730.

7. Kesselheim AS, Misono AS, Lee JL, et al. Clinical equivalence of generic and brand-name drugs used in cardiovascular disease: a systematic review and meta-analysis. JAMA. 2008;300(21):2514-2526.

8. Kalisch LM, Roughead EE, Gilbert AL. Brand substitution or multiple switches per patient? An analysis of pharmaceutical brand substitution in Australia. Pharmacoepidemiol Drug Saf. 2008;17:620-625.

9. Shrank WH, Cox ER, Fischer MA, Mehta J, Choudhry NK. Patients' perceptions of generic medications. Health Aff (Millwood). 2009;28(2):546-556.

10. Shrank WH, Liberman JN, Fischer MA, et al. Physician perceptions about generic drugs. Ann Pharmacother. 2011;45:31-38.

11. Duerden MG, Hughes DA. Generic and therapeutic substitutions in the UK: are they a good thing? Br J Clin Pharmacol. 2010;70:335-341.

12. Andersson K, Bergstrom G, Petzold MG, Carlsten A. Impact of a generic substitution reform on patients' and society's expenditure for pharmaceuticals. Health Policy. 2007;81:376-384.

13. Fujii H, Iihara H, Yasuda K, et al. Evaluation of efficacy and safety of generic levofolinate in patients who received colorectal cancer chemotherapy. Med Oncol. 2011;28(2):488-493.

14. Gilman JT, Alvarez LA, Duchowny M. Carbamazepine toxicity resulting from generic substitution. Neurology. 1993;43(12):2696-2697.

15. Shaw JE, Sicree RA, Zimmet PZ. Global estimates of the prevalence of diabetes for 2010 and 2030. Diabetes Res Clin Pract. 2010;87:4-14.

16. Alexander GC, Sehgal NL, Moloney RM, Stafford RS. National trends in treatment of type 2 diabetes mellitus, 1994-2007. Arch Intern Med. 2008;168:2088-2094.

17. American Diabetes Association. Standards of medical care in diabetes Diabetes Care. 2004;27 Suppl 1:S15-S35.

18. Soenarya S. Application of the ATC/DDD methodology to measure antibiotic utilization for treatment of hospitalized patients with community-acquired pneumonia at an Indonesian hospital. Pharm World Sci. 2009;31:329-329.

19. Van Wijk BLG, Klungel OH, Heerdink ER, de Boer A. Generic substitution of antihypertensive drugs: does it affect adherence? Ann Pharmacother. 2006;40:15-20.

20. Rodin HA, Heaton AH, Wilson AR, Garrett NA, Plocher DW. Plan designs that encourage the use of generic drugs over brand-name drugs: an analysis of a free generic benefit. Am J Manag Care. 2009;15: 881-888.
21. Deyo RA, Cherkin DC, Ciol MA. Adapting a clinical comorbidity index for use with ICD-9-CM administrative databases. J Clin Epidemiol. 1992;45:613-619.

22. Yates AP, Laing I. Age-related increase in haemoglobin A1c and fasting plasma glucose is accompanied by a decrease in beta cell function without change in insulin sensitivity: evidence from a cross-sectional study of hospital personnel. Diabet Med. 2002;19:254-258.

23. Hellström J, Rudholm N. Uncertainty in the generic versus brand name prescription decision. Empir Econ. 2010;38:503-521.

24. Paraponaris A, Verger P, Desquins B, et al. Delivering generics without regulatory incentives? Empirical evidence from French general practitioners about willingness to prescribe international non-proprietary names. Health Policy. 2004;70:23-32.

25. Chua GN, Hassali MA, Shafie AA, Awaisu A. A survey exploring knowledge and perceptions of general practitioners towards the use of generic medicines in the northern state of Malaysia. Health Policy. 2010;95:229-235.

26. Tsiantou V, Zavras D, Kousoulakou H, et al. Generic medicines: Greek physicians' perceptions and prescribing practices. J Clin Pharm Ther. 2009;34:547-554.

27. Ferner RE, Lenney W, Marriott JF. Controversy over generic substitution. BMJ. 2010;340:c2548

28. Wiernsperger NF, Bailey CJ. The antihyperglycaemic effect of metformin - therapeutic and cellular mechanisms. Drugs. 1999;58: 31-39.

29. Charpentier G, Fleury F, Kabir M, et al. Improved glycaemic control by addition of glimepiride to metformin monotherapy in type 2 diabetic patients. Diabet Med. 2001;18:828-834

30. Arechavaleta R, Seck T, Chen Y, et al. Efficacy and safety of treatment with sitagliptin or glimepiride in patients with type 2 diabetes inadequately controlled on metformin monotherapy: a randomized, double-blind, non-inferiority trial. Diabetes Obes Metab. 2011;13: 160-168.

31. Wright A, Burden AC, Paisey RB, Cull CA, Holman RR; UK Prospective Diabetes Study Group. Sulfonylurea inadequacy: efficacy of addition of insulin over 6 years in patients with type 2 diabetes in the UK Prospective Diabetes Study (UKPDS 57). Diabetes Care. 2002;25:330-336.

32. Oiknine R, Mooradian AD. Drug therapy of diabetes in the elderly. Biomed Pharmacother. 2003;57(5-6):231-239.

33. El-Kebbi IM, Cook CB, Ziemer DC, et al. Association of younger age with poor glycemic control and obesity in urban African Americans with type 2 diabetes. Arch Intern Med. 2003;163:69-75.

34. Schectman JM, Nadkarni MM, Voss JD. The association between diabetes metabolic control and drug adherence in an indigent population. Diabetes Care. 2002;25:1015-1021.

35. Pladevall M, Williams LK, Potts LA, et al. Clinical outcomes and adherence to medications measured by claims data in patients with diabetes Diabetes Care. 2004;27:2800-2805.
Patient Preference and Adherence

\section{Publish your work in this journal}

Patient Preference and Adherence is an international, peer-reviewed, open access journal focusing on the growing importance of patient preference and adherence throughout the therapeutic continuum. Patient satisfaction, acceptability, quality of life, compliance, persistence and their role in developing new therapeutic modalities and compounds to

\section{Dovepress}

optimize clinical outcomes for existing disease states are major areas of interest. This journal has been accepted for indexing on PubMed Central. The manuscript management system is completely online and includes a very quick and fair peer-review system. Visit http://www.dovepress.com/ testimonials.php to read real quotes from published authors. 